\title{
DENSE MEDIA CYCLONE OPTIMIZATION
}

Report Type: Quarterly Technical Progress Report

Reporting Period: April 1, 2001 - June 30, 2001

Principal Author: Gerald H. Luttrell

Submission Date: September 10, 2001 (Revised September 14, 2002)

DOE Number: DE-FC26-01NT41061

NETL Manager: David M. Hyman

Submitting Organization:

Department of Mining \& Minerals Engineering 100 Holden Hall

Virginia Polytechnic Institute \& State University

Blacksburg, VA 24061

Other Participants:

Massey Coal Services

Partition Enterprises

Precision Testing Laboratories

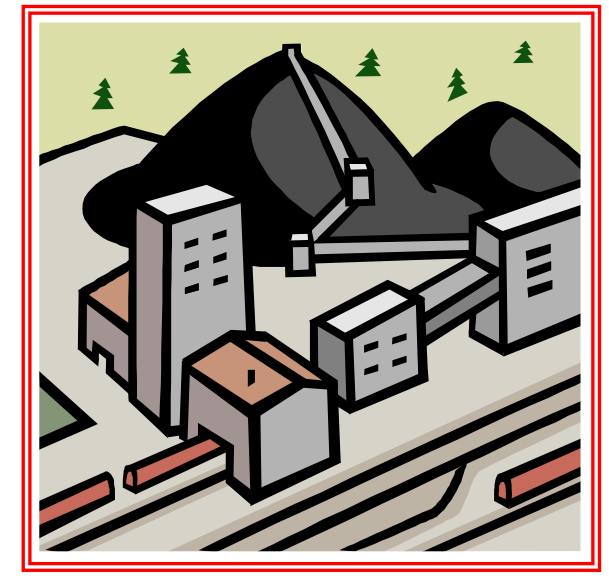




\section{DISCLAIMER}

This report was prepared as an account of work sponsored by an agency of the United States Government. Neither the United States Government nor any agency thereof, nor any of their employees, makes any warranty, express or implied, or assumes any legal liability or responsibility for the accuracy, completeness, or usefulness of any information, apparatus, product, or process disclosed, or represents that its use would not infringe privately owned rights. Reference herein to any specific commercial product, process, or service by trade name, trademark manufacturer, or otherwise does not necessarily constitute or imply its endorsement, recommendation, or favoring by the United States Government or any agency thereof. The views and opinions of authors expressed herein do not necessarily state or reflect those of the United States Government or any agency thereof. 


\section{ABSTRACT}

The fieldwork associated with Task 1 (Baseline Assessment) was completed this quarter. Detailed cyclone inspections completed at all but one plant during maintenance shifts. Analysis of the test samples is also currently underway in Task 4 (Sample Analysis). A Draft Recommendation was prepared for the management at each test site in Task 2 (Circuit Modification). All required procurements were completed. Density tracers were manufactured and tested for quality control purposes. Special sampling tools were also purchased and/or fabricated for each plant site. The preliminary experimental data show that the partitioning performance for all seven HMC circuits was generally good. This was attributed to well-maintained cyclones and good operating practices. However, the density tracers detected that most circuits suffered from poor control of media cutpoint. These problems were attributed to poor k-ray calibration and improper manual density measurements. These conclusions will be validated after the analyses of the composite samples have been completed. 


\section{Dense Medium Cyclone Optimization (Proposal \#60)}

- Principal Investigator:

- NETL Project Manager:

- Partners:

- Total Project Cost:

- DOE Share:

- Participant Share:

- Project Period:

- Project Start Date:
Gerald Luttrell (Virginia Tech)

David M. Hyman

Massey Coal Services Partition Enterprises (Australia) Precision Testing

$\$ 320 \mathrm{~K}$ $\$ 154 \mathrm{~K}$ \$166K

12 months

14 Dec. 2000

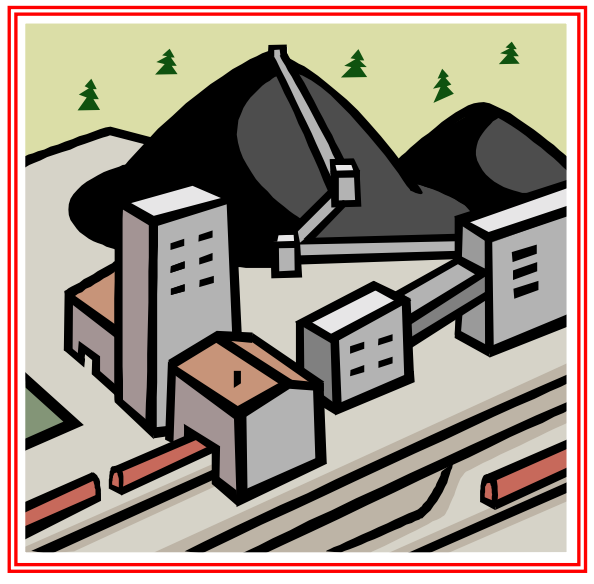

April-June 2001 Quarterly Report 


\section{Background}

- Heavy Media Cyclones (HMCs)

- Serves as the "workhorse" in the coal preparation industry for removing waste rock from valuable coal

- In the U.S., HMCs represent an installed capacity of $>85,000$ ton/hr

- Problem - Improper operation can result in large losses of recoverable coal to the waste product

- losses estimated to be more than \$45 million annually

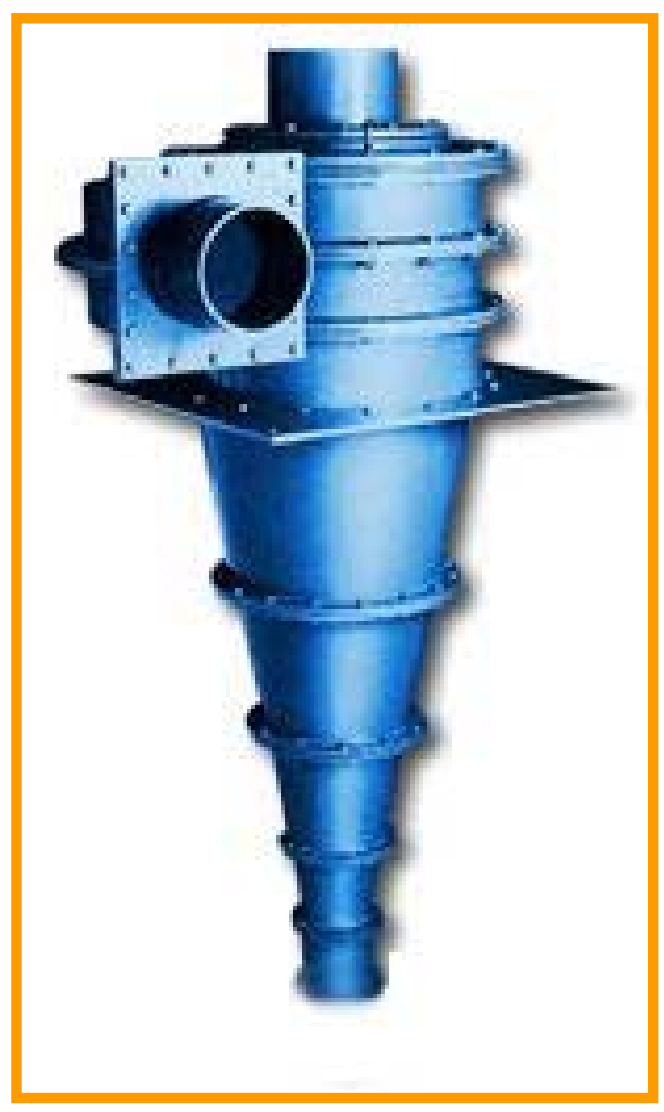




\section{Project Objectives}

- To develop a set of three basic engineering tools to improve the efficiency of heavy medium cyclone (HMC) circuits:

- low cost tracers to rapidly assess HMC performance

- mathematical process models to predict the influence of changes in operating and design variables on HMC performance

- model-based expert system to provide operators with a user-friendly interface for evaluating, optimizing, and troubleshooting HMC circuits

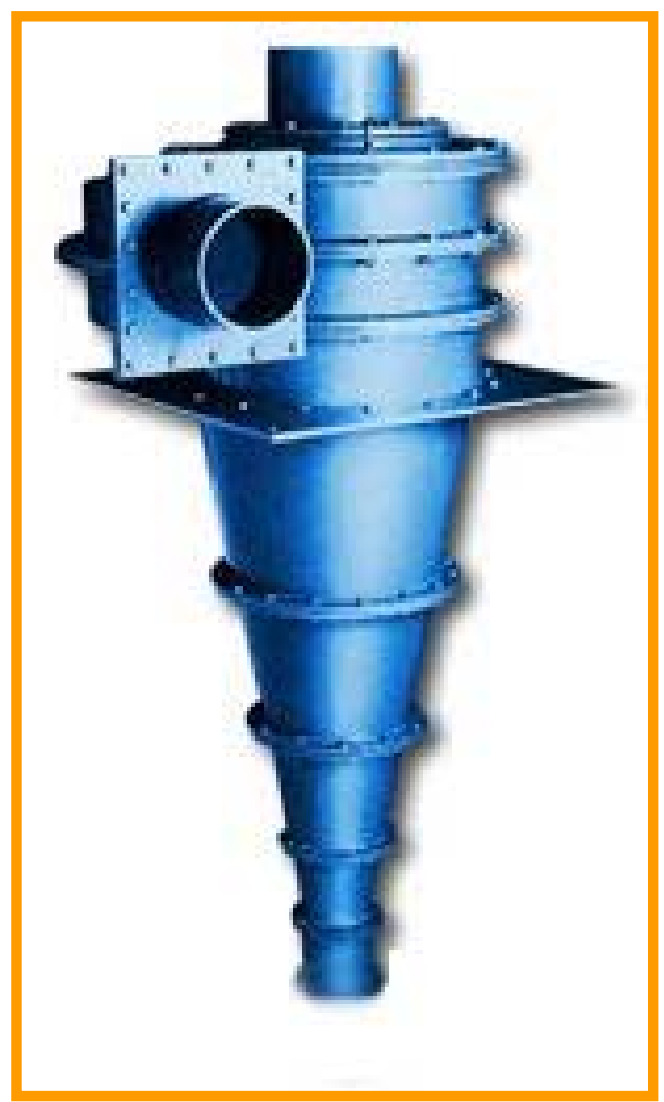




\section{Simulations Showing Economic Impact of Improper Density Cutpoints}

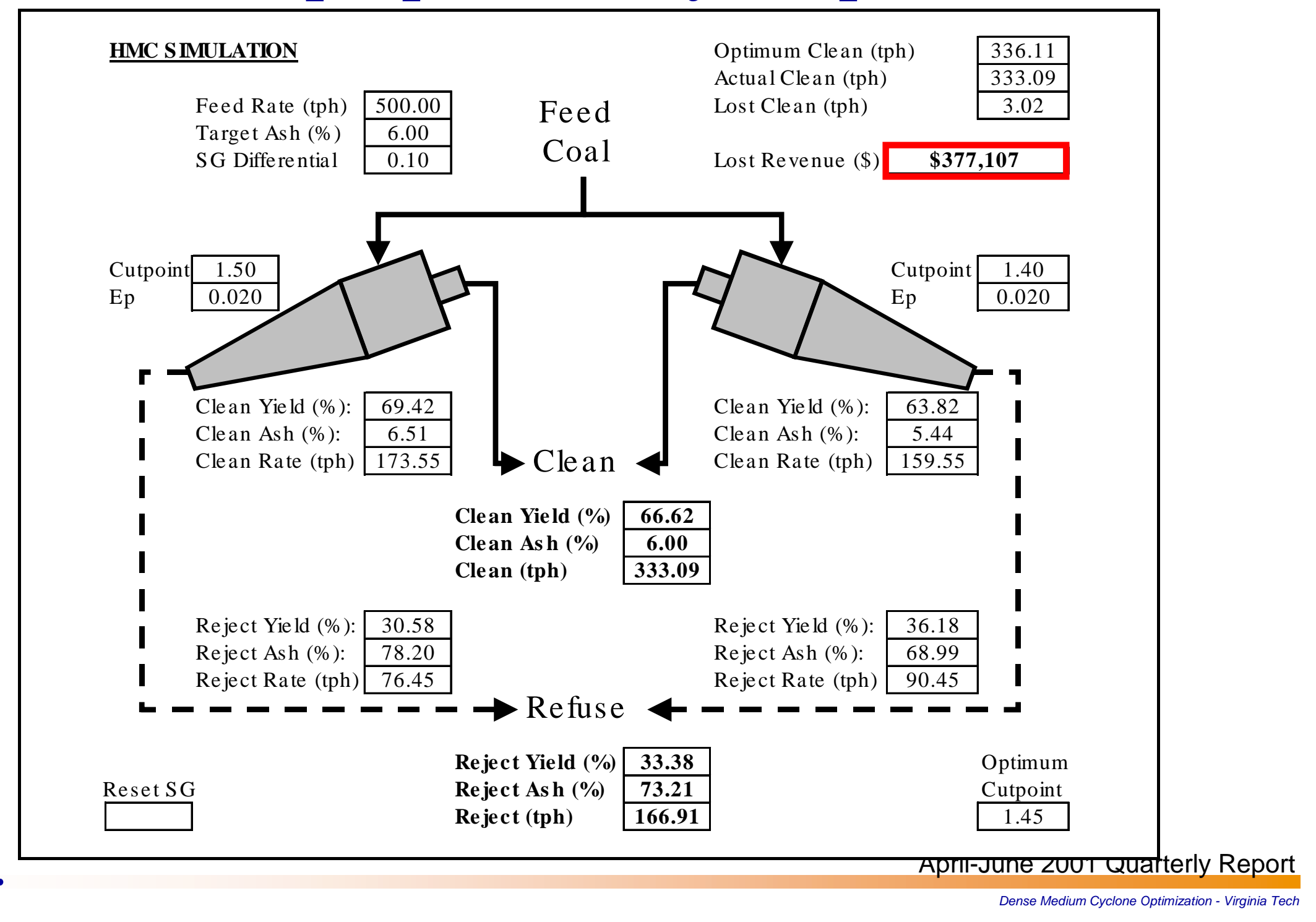




\section{Photo Library}
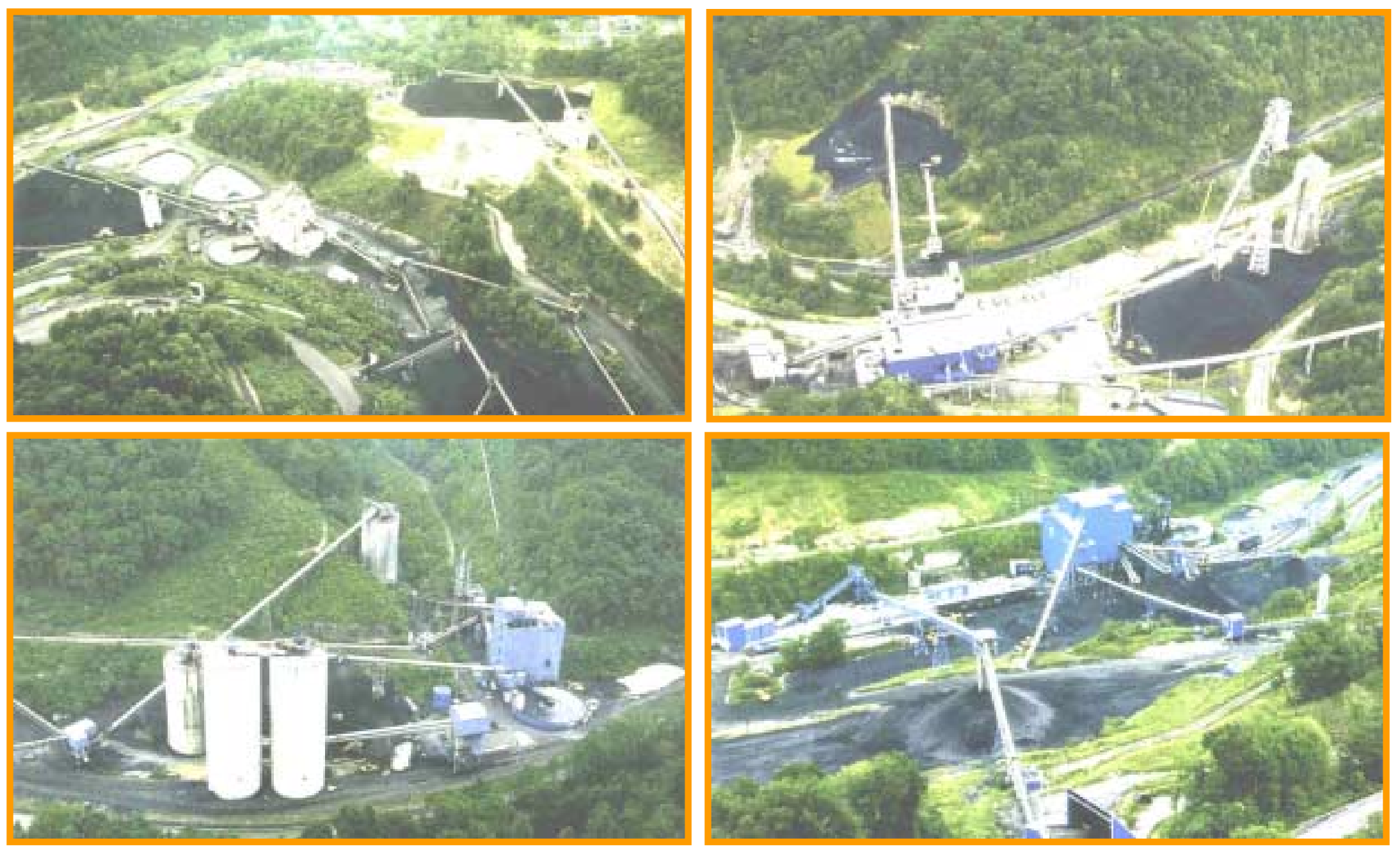

Photographs of several of the industrial coal preparation plants where the field testing of the heavy media cyclones is being performed 2001 Quarterly Report 


\section{Photo Library}

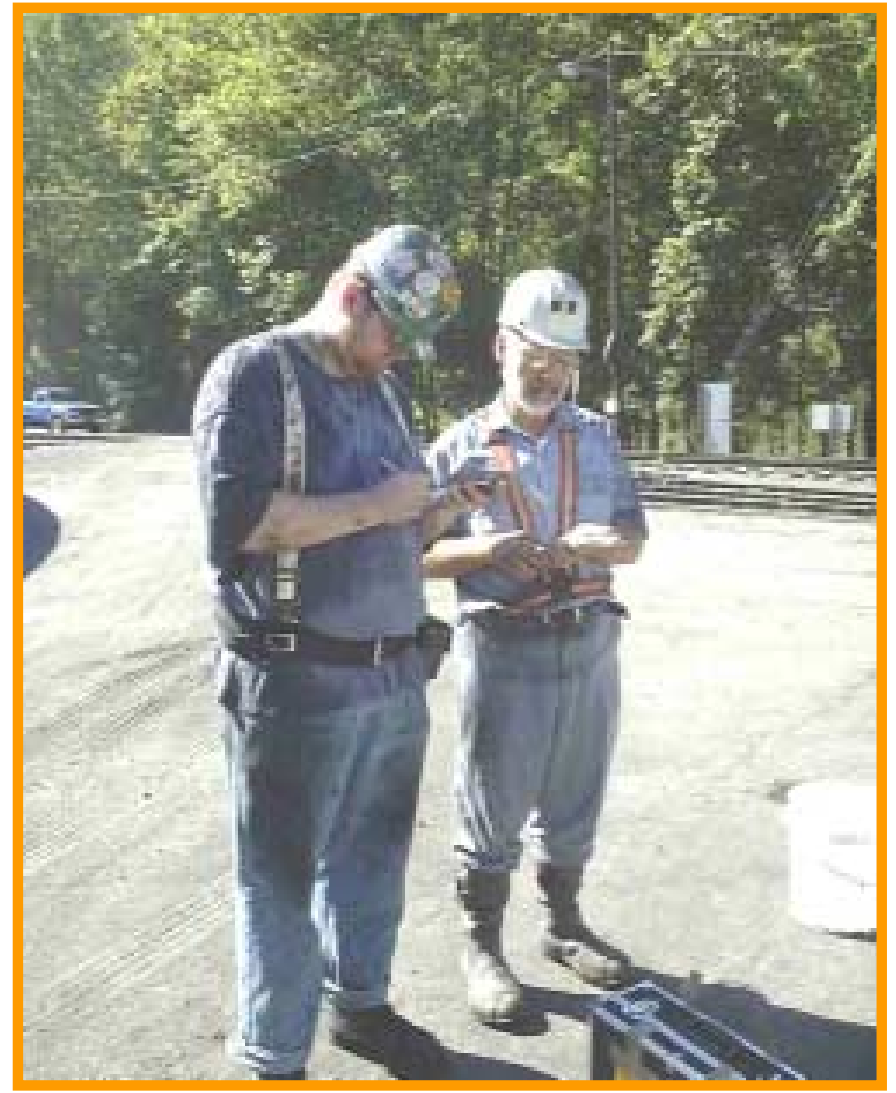

Shane Bomar (graduate student) and Chris Wood (Partition Enterprises) preparing for plant sampling and density tracer testing.

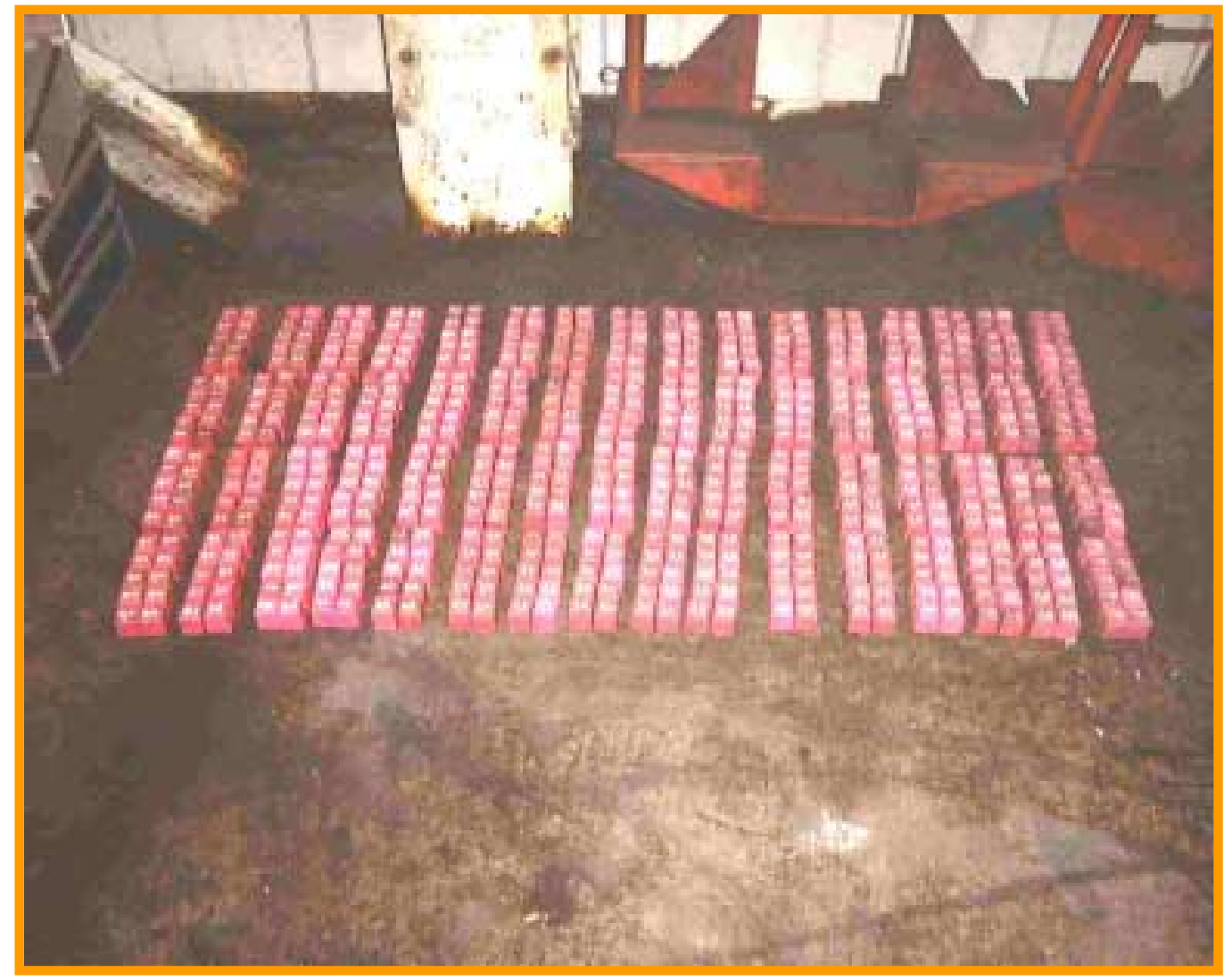

Density tracers (32 $\mathrm{mm}$ cubes) sorted into groups of 20 each (1.32 to $2.50 \mathrm{SG}$ ) just prior to being introduced into the cyclone feed stream. 


\section{Photo Library}

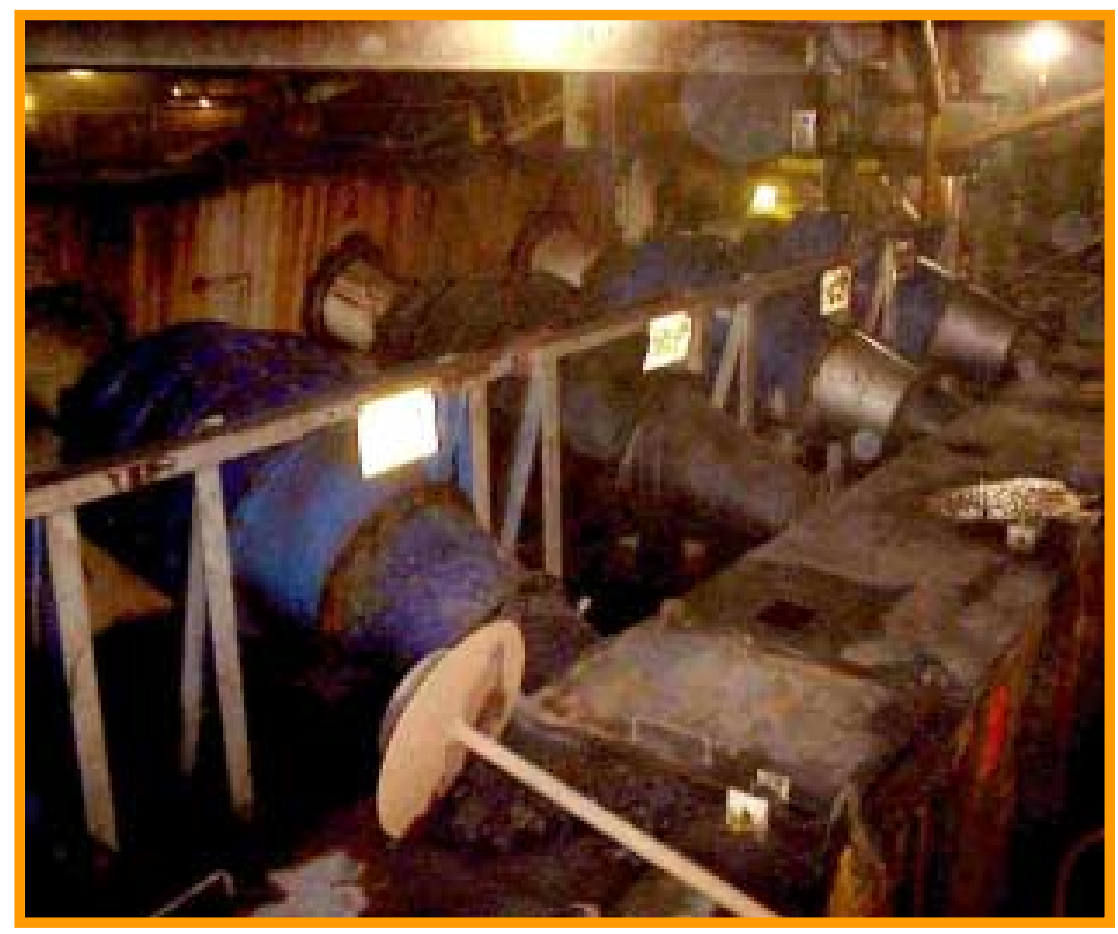

A bank of parallel coarse coal heavy media cyclones that were sampled in detail and evaluated using the density tracers .

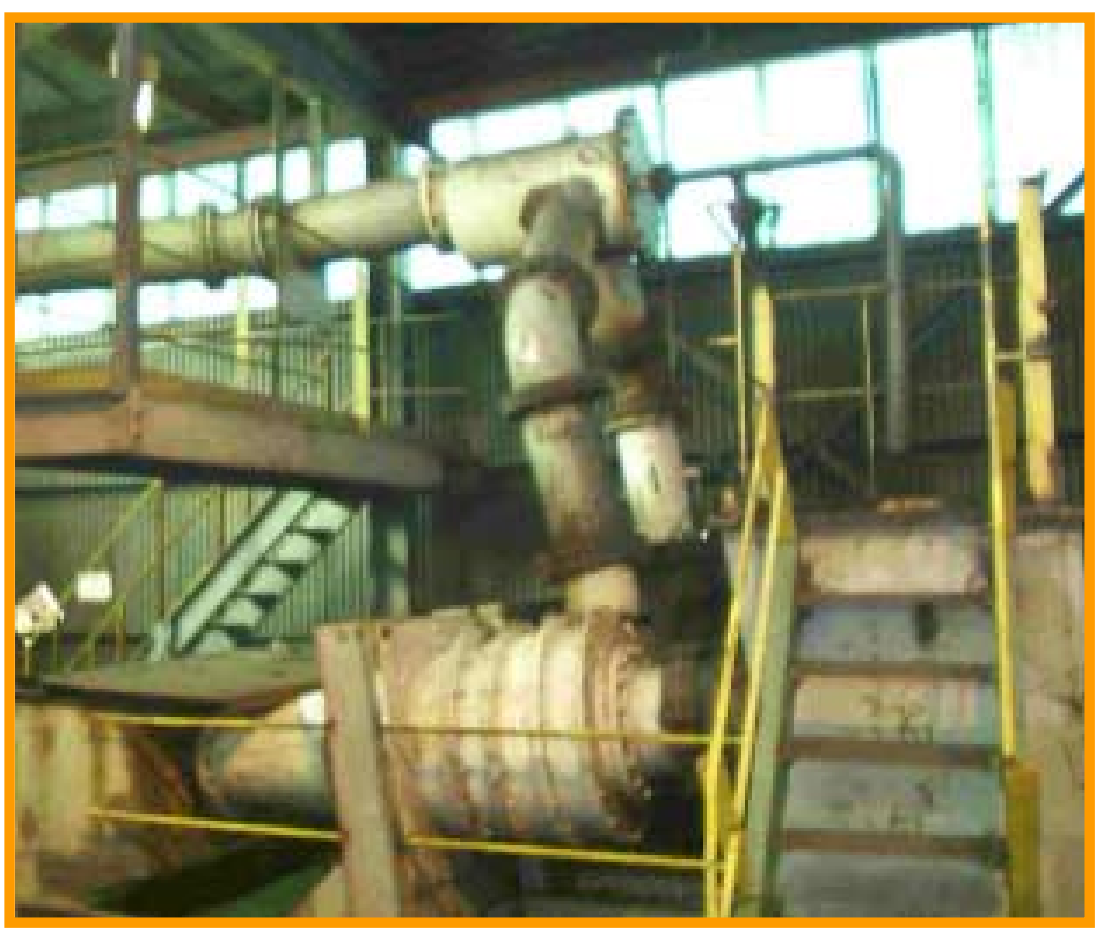

An installation of twin parallel coarse coal heavy media cyclones that were sampled in detail and evaluated using the density tracers . 


\section{Photo Library}

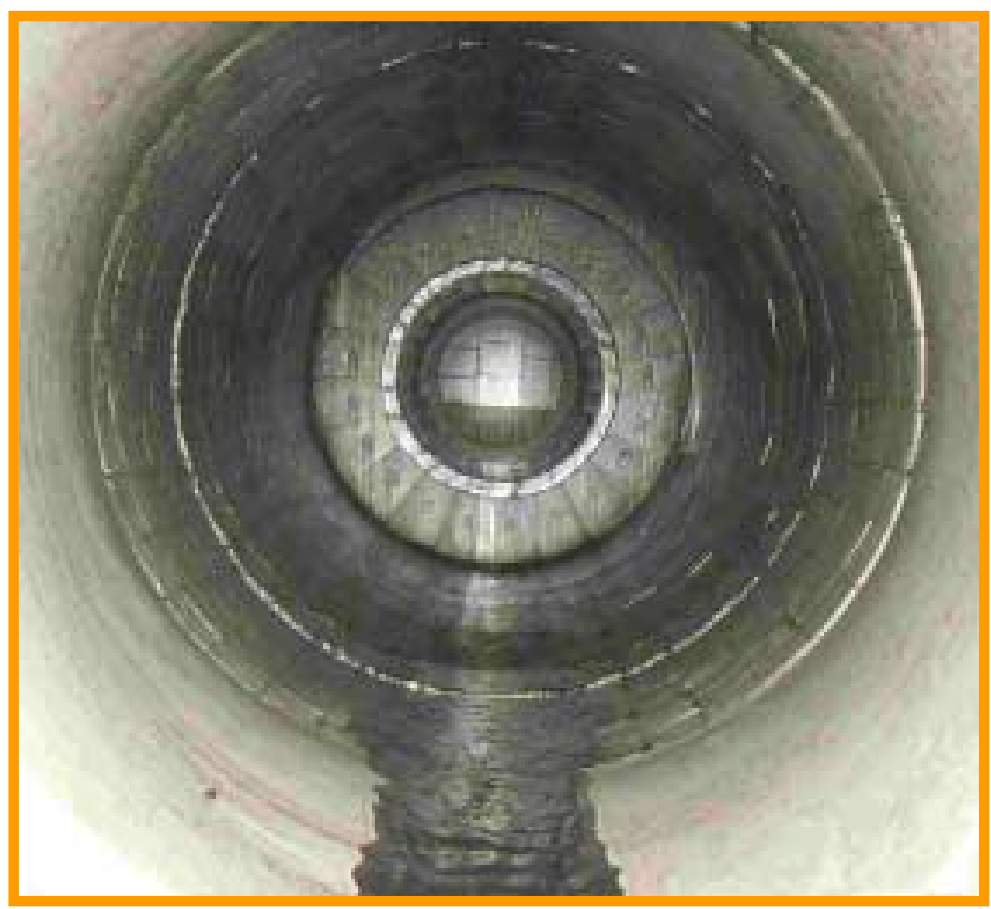

Inside view of a ceramic-lined heavy media cyclone obtained during the preliminary site inspections (as viewed through the apex).

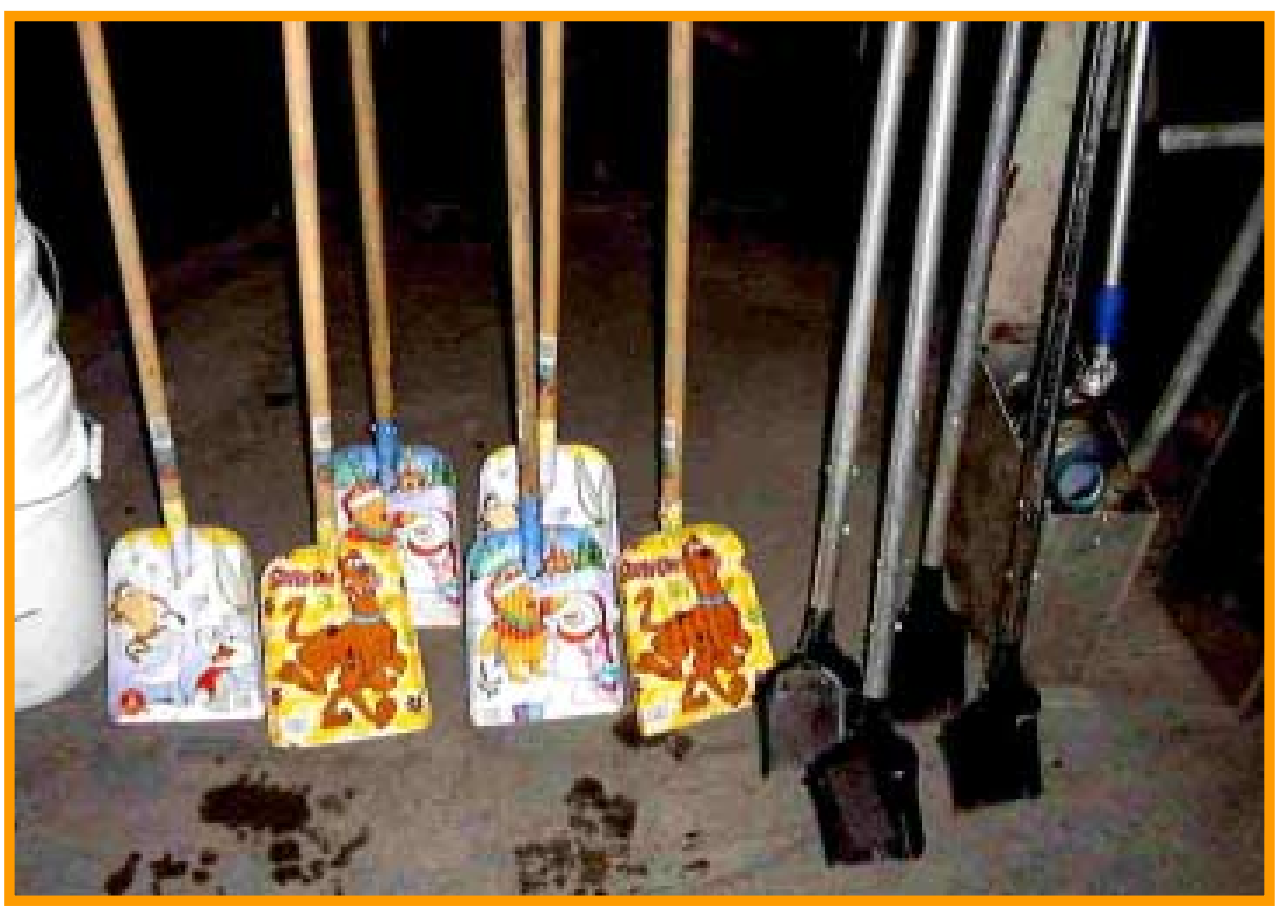

Examples of sampling tools that were purchased or fabricated for the collection of density tracers and samples of clean coal, refuse and circulating media. 


\section{Photo Library}

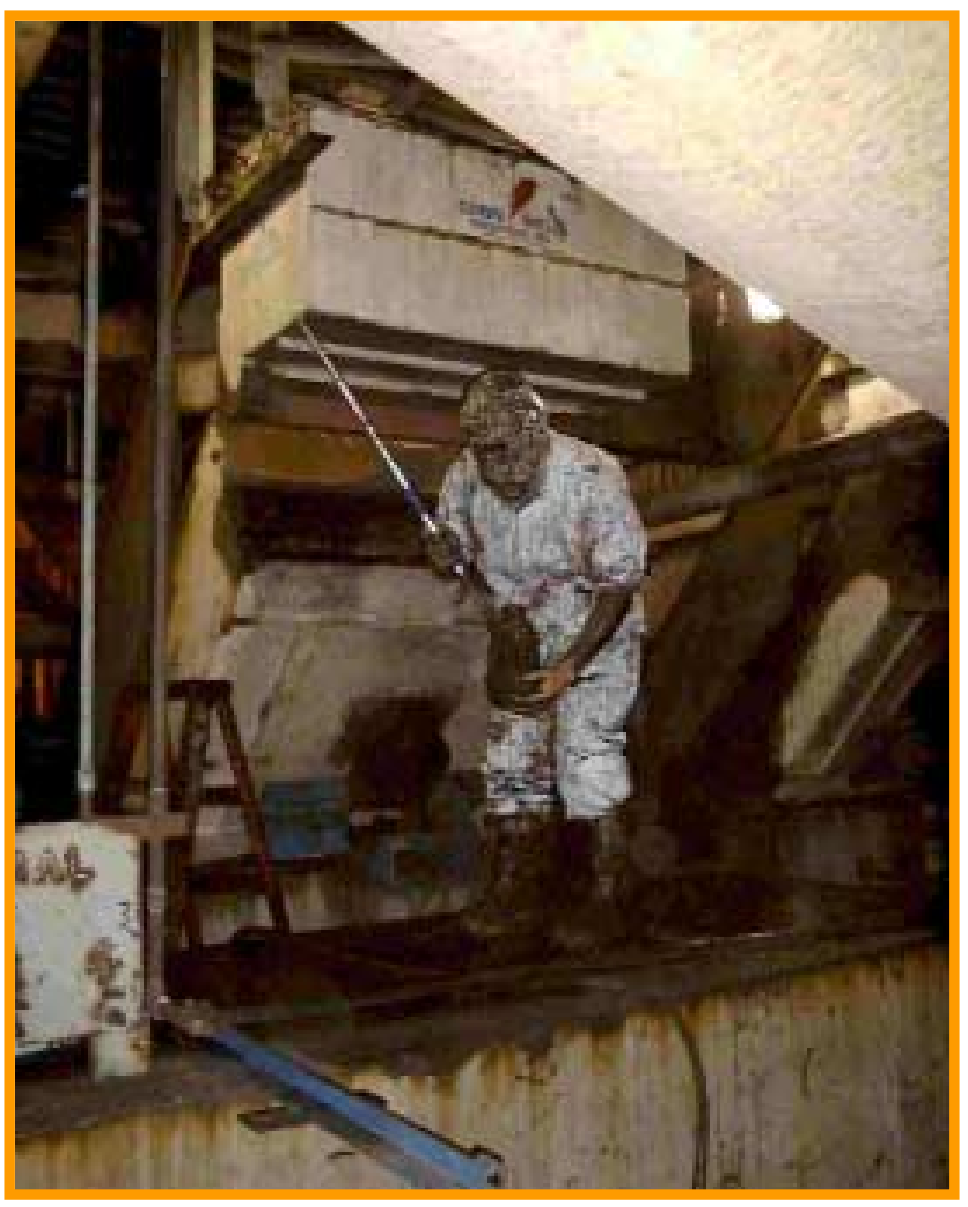

Photograph showing the collection of a sample of circulating media from the underside of the clean coal sieve.

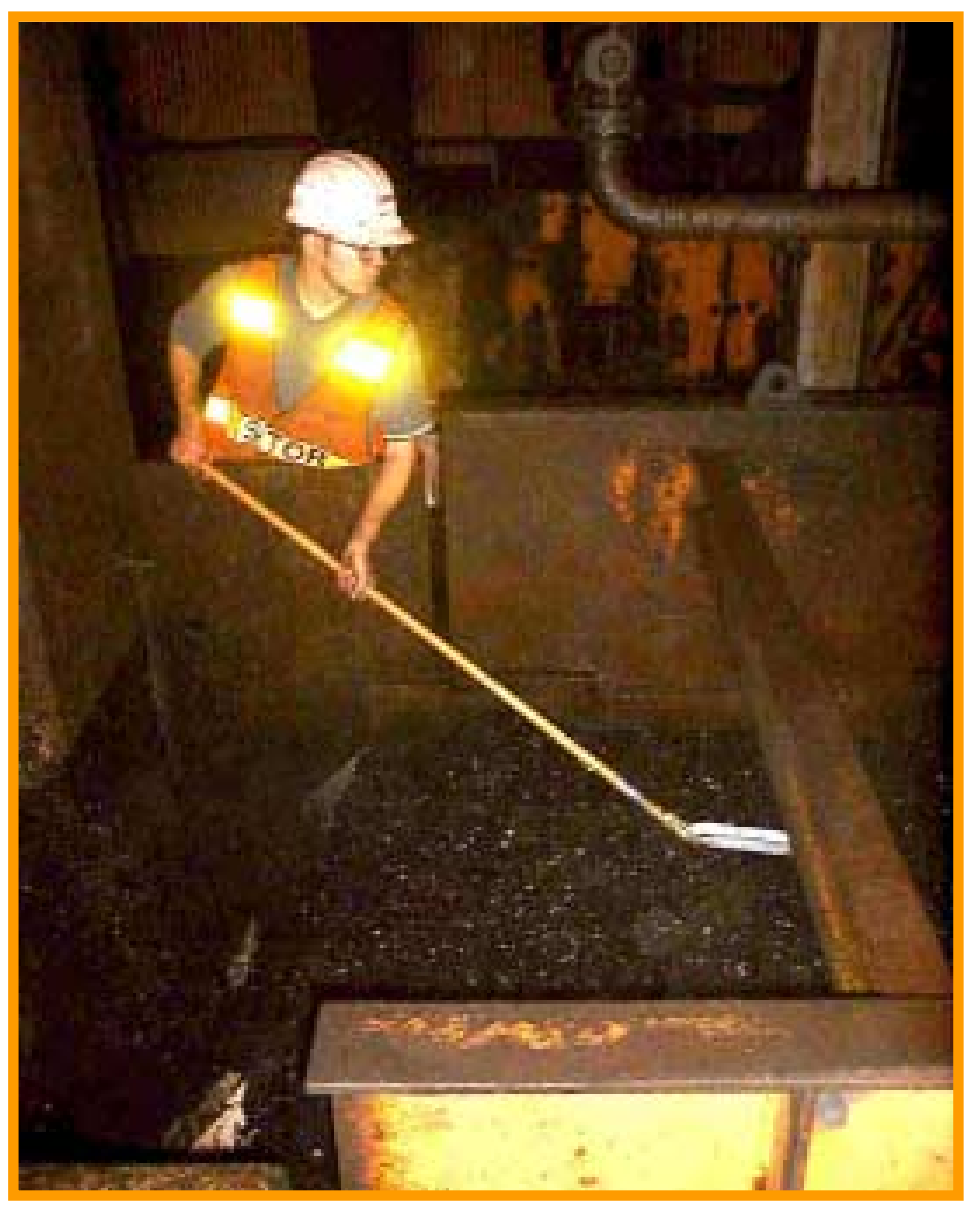

Photograph showing the collection of density tracers from the clean coal drain-and-rinse screens below a bank heavy media cyclones.

April-June 2001 Quarterly Report 


\section{Project Cost Summary}

\begin{tabular}{|l|cc|cc|cc|cc|}
\hline \multirow{2}{*}{ Source } & \multicolumn{2}{|c|}{ First Year } & \multicolumn{2}{c|}{ Second Year } & \multicolumn{2}{c|}{ Third Year } & \multicolumn{2}{c|}{ Totals } \\
\cline { 2 - 9 } & Plan & Actual & Plan & Actual & Plan & Actual & Plan & Actual \\
\hline Participant & $\$ 166 \mathrm{~K}$ & --- & 0 & --- & 0 & --- & $\$ 166 \mathrm{~K}$ & --- \\
DOE & $\$ 154 \mathrm{~K}$ & --- & 0 & --- & 0 & --- & $\$ 154 \mathrm{~K}$ & --- \\
\hline Total & $\$ 320 \mathrm{~K}$ & --- & 0 & --- & 0 & --- & $\$ 320 \mathrm{~K}$ & --- \\
\hline
\end{tabular}

KEY:

Plan = Planned costs for the full year.

Actual $=$ Actual costs through the reporting period. 


\section{Milestones and Status}

\begin{tabular}{|c|c|c|}
\hline Project Milestone & Target Date & Status of Proposed Work \\
\hline 1 - Baseline Assessment & Aug. 01 & $\begin{array}{c}\text { Field Work Completed/Data } \\
\text { Analysis Underway }\end{array}$ \\
\hline 2 - Circuit Modification & Sept. 01 & $\begin{array}{l}\text { Draft Recommendation in } \\
\text { Preparation for Each Plant }\end{array}$ \\
\hline 3 - Follow-Up Assessment & July/Nov. 01 & $\begin{array}{l}2+2 \\
--- \\
--\end{array}$ \\
\hline 4 - Sample Analysis & Monthly & $\begin{array}{l}\text { Size Analyses Completed \& Float- } \\
\text { Sink Tests Underway }\end{array}$ \\
\hline 5 - Analysis/Simulation & Monthly & $\begin{array}{l}\text { Data Analysis in Progress / } \\
\text { Circuit Simulation Underway }\end{array}$ \\
\hline 6 - Expert System Dev. & Nov. 01 & 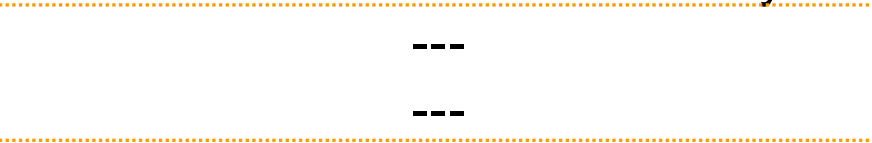 \\
\hline 7 - Concept Assessment & Dec. 01 & -- \\
\hline
\end{tabular}




\section{Key Accomplishments}

- All required procurements completed

- Density tracers manufactured and tested for quality control purposes

- Special sampling tools purchased and/or fabricated for each plant site

- Baseline Assessment completed

- Five different plants visited and evaluated (only four proposed)

- Seven different cyclone circuits fully examined, sampled and tested (active participation of up to 14 personnel)

- Detailed cyclone inspections completed at all but one plant during maintenance shifts 


\section{Key Accomplishments (continued)}

- Baseline Assessment completed (continued)

- In-plant testing procedure:

- Establish stable operation under required conditions

- Make multiple manual measurements of the densities of feed, overflow and underflow media

- Conduct density tracer tests using 32 or $16 \mathrm{~mm}$ tracers (as appropriate)

- Take composite samples of circulating media, feed coal, clean coal, and refuse for later analysis (particle size, float-sink, ash analysis, etc.)

- Estimate mass flow rates by taking timed samples

- Record plant operating conditions 


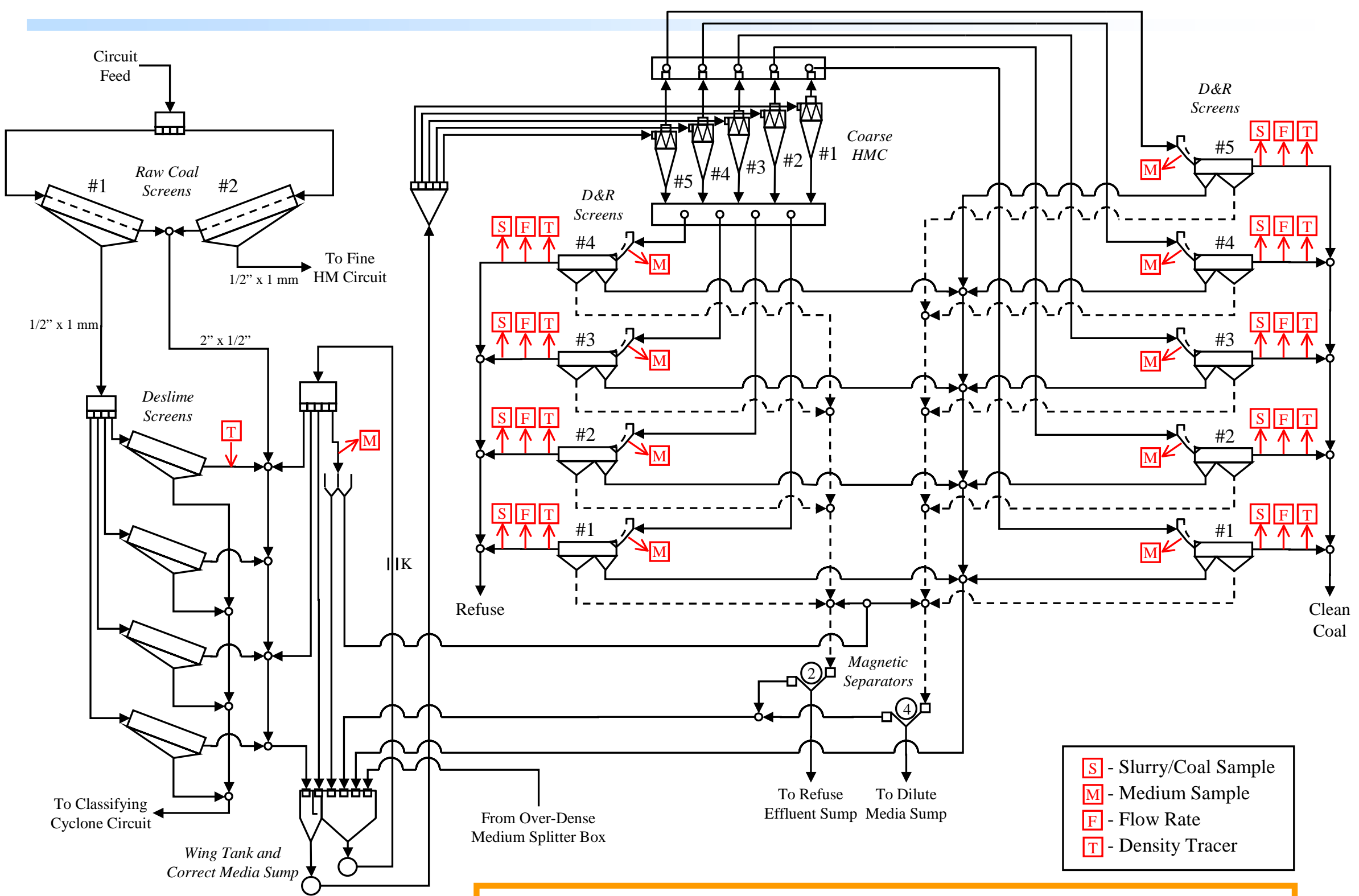

Flowsheet for one of the heavy media circuits evaluated in this project . 


\section{Example of Density Tracer Data Obtained During the Preliminary Assessment}

\section{Density Tracer Partition Curve}

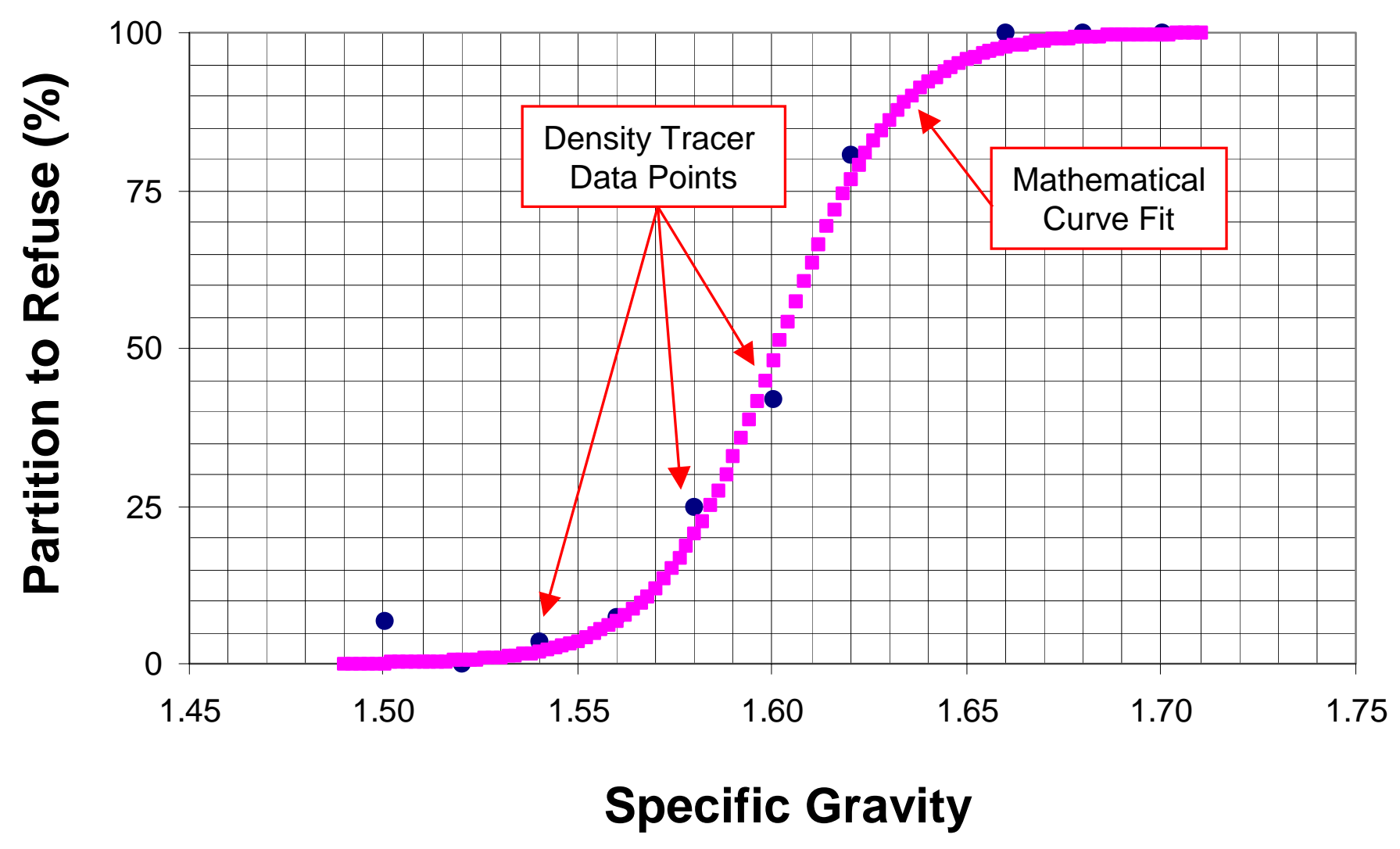




\section{Good News!}

- The partitioning performance for all 7 circuits was generally good.

- Attributed to well maintained cyclones and good operating practices.

- Density tracers detected that most circuits suffered from poor control of media cutpoint.

- Problems attributed to poor k-ray calibration and improper manual density measurements.

- Very important for plants that also have heavy media baths since poor control can have a significant impact on plant profitability.

- More will be known after the analyses of the composite samples have been completed. 


\section{Good News!}

- Other problems identified by tracers...

- Plant A: Performance good, but feed distribution problem observed; media readings incorrect.

- $\underline{\text { Plant B }}$ : Evidence of recoverable coal misplaced to refuse due to overload.

- Plant C: Recoverable coal misplaced to refuse at low SG cutpoints (overload or surging); media reading incorrect.

- Plant D: Cyclones suffering from severe overload; media readings incorrect.

- Plant E: Performance good, but cutpoint lower than expected (probably due to overload)

- Conclusion - Density tracers very effective in identifying operating problems. 


\section{Project Recognition}

- International Conferences

- "Optimization of Heavy Media Cyclone Circuits," Accepted for publication and presentation at the 2002 Annual Meeting of the Society for Mining, Exploration and Metallurgy (SME), Salt Lake City, Utah

- Short Courses and Workshops

- "An Introduction to Coal Preparation," One-Day Short Course, Sponsored by Coal Prep 2001 International Exhibition and Conference, Lexington, KY, April 30, 2001, 66 attendees.

- Operating and Maintenance Standards for Heavy Media Cyclones," Half-Day Workshop, Sponsored by Massey Coal Services, Chapmanville, WV, February 9, 2001, 18 attendees.

- "Operating and Maintenance Standards for Heavy Media Cyclones," Half-Day Workshop, Sponsored by Massey Coal Services, Chapmanville, WV, March 9, 2001, 11 attendees.

- "Operating and Maintenance Standards for Heavy Media Cyclones," Half-Day Workshop, Sponsored by TECO Coal Company, Dunbar, KY, June 12, 2001, 14 attendees.

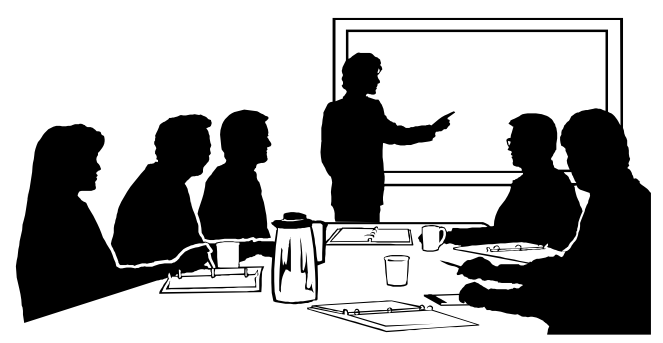

April-June 2001 Quarterly Report 


\section{Project Assessment (Internal DOE Use Only)}

- Open Issues and/or Problems

- None noted

- All project activities on schedule

- Spending to date within budget limits

- Overall Assessment

- Off to a good start

-Findings to date of significant technical and economic importance
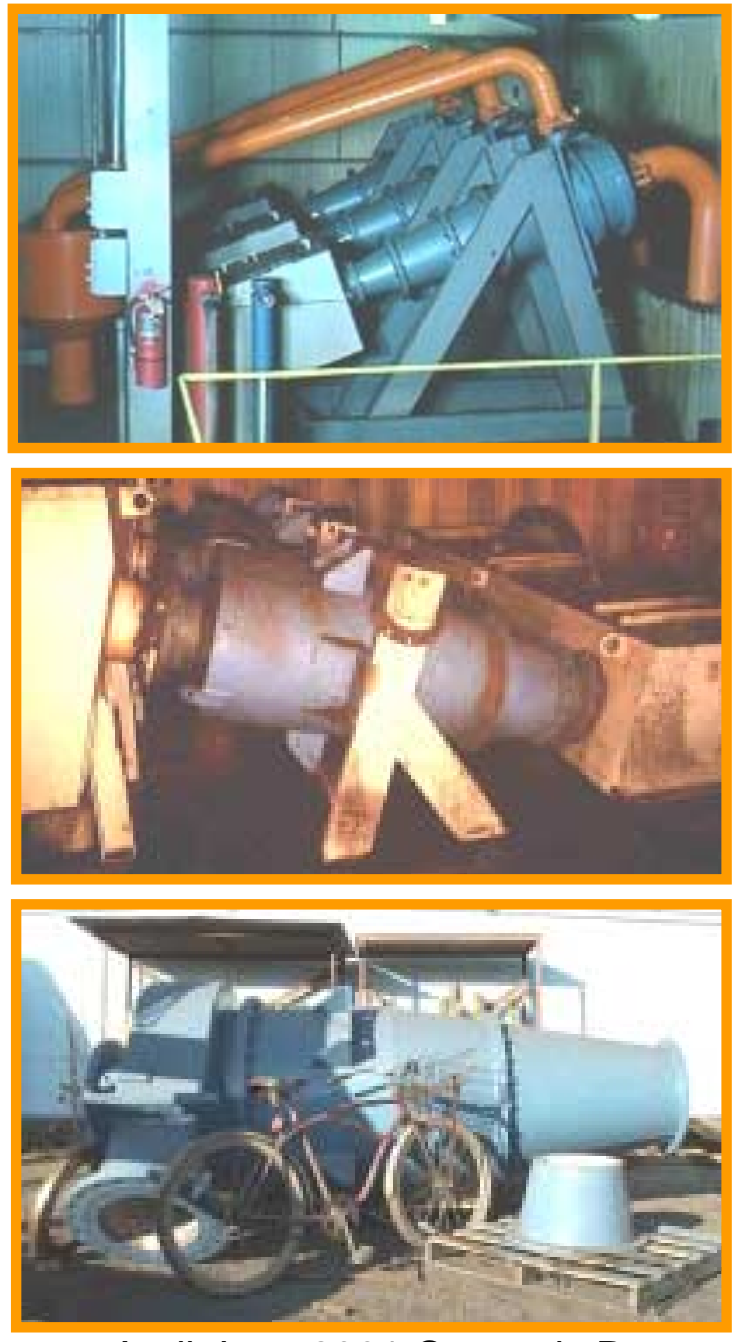